\title{
Increased Number of Cerebellar Granule Cells and Astrocytes in the Internal Granule Layer in Sheep Following Prenatal Intra-amniotic Injection of Lipopolysaccharide
}

\author{
Eveline Strackx • Markus Gantert • Veronique Moers • Imke A. J. van Kooten • \\ Rebecca Rieke - Hanna Hürter • Marijke A. M. Lemmens • Harry W. M. Steinbusch • \\ L. J. I. Zimmermann • Johannes S. H. Vles • Yves Garnier • Antonio W. D. Gavilanes • \\ Boris W. Kramer
}

Published online: 20 July 2011

(C) The Author(s) 2011. This article is published with open access at Springerlink.com

\begin{abstract}
Chorioamnionitis is an important problem in perinatology today, leading to brain injury and neurological handicaps. However, there are almost no data available regarding chorioamnionitis and a specific damage of the cerebellum. Therefore, this study aimed at determining if chorioamnionitis causes cerebellar morphological alterations. Chorioamnionitis was induced in sheep by the intra-
\end{abstract}

E. Strackx $\cdot$ V. Moers $\cdot$ I. A. J. van Kooten $\cdot$ R. Rieke $\cdot$ H. Hürter M. A. M. Lemmens $\cdot$ H. W. M. Steinbusch • A. W. D. Gavilanes • B. W. Kramer

Department of Neuroscience and European Graduate School of Neuroscience (EURON), Maastricht University,

Maastricht, The Netherlands

E. Strackx $\cdot$ R. Rieke $\cdot$ H. Hürter $\cdot$ L. J. I. Zimmermann •

A. W. D. Gavilanes $\cdot$ B. W. Kramer

Department of Pediatrics/Neonatology,

Maastricht University Medical Center,

Maastricht, The Netherlands

M. Gantert $\cdot$ Y. Garnier

Department of Obstetrics and Gynecology, Klinikum Osnabrück, Osnabrück, Germany

V. Moers · J. S. H. Vles

Department of Child Neurology,

Maastricht University Medical Center,

Maastricht, The Netherlands

\author{
A. W. D. Gavilanes $(\bowtie)$ \\ Department of Pediatrics, Maastricht University Medical Center, \\ P. Debyelaan 25, \\ 6202 AZ, Maastricht, The Netherlands \\ e-mail: danilo.gavilanes@mumc.nl
}

amniotic injection of lipopolysaccharide (LPS) at a gestational age (GA) of 110 days. At a GA of 140 days, we assessed the mean total and layer-specific volume and the mean total granule cell (GCs) and Purkinje cell (PC) number in the cerebelli of LPS-exposed and control animals using high-precision design-based stereology. Astrogliosis was assessed in the gray and white matter (WM) using a glial fibrillary acidic protein staining combined with gray value image analysis. The present study showed an unchanged volume of the total cerebellum as well as the molecular layer, outer and inner granular cell layers (OGL and IGL, respectively), and WM. Interestingly, compared with controls, the LPS-exposed brains showed a statistically significant increase $(+20.4 \%)$ in the mean total number of GCs, whereas the number of PCs did not show any difference between the two groups. In addition, LPS-exposed animals showed signs of astrogliosis specifically affecting the IGL. Intra-amniotic injection of LPS causes morphological changes in the cerebellum of fetal sheep still detectable at full-term birth. In this study, changes were restricted to the inner granule layer. These cerebellar changes might correspond to some of the motor or non-motor deficits seen in neonates from compromised pregnancies.

Keywords Chorioamnionitis · LPS · Intra-amniotic · Fetal · Cerebellum · Granule cell loss · Astrocytes · Stereology

$\begin{array}{ll}\text { Abbreviations } \\ \text { GA } & \text { Gestational age } \\ \text { GCs } & \text { Granule cells } \\ \text { GD } & \text { Gestational day }\end{array}$




$\begin{array}{ll}\text { GFAP } & \text { Glial fibrillary acidic protein } \\ \text { IGL } & \text { Inner granular layer } \\ \text { IL } & \text { Interleukin } \\ \text { IFN } & \text { Interferon } \\ \text { LPS } & \text { Lipopolysaccharide } \\ \text { ML } & \text { Molecular layer } \\ \text { NF-kB } & \text { Nuclear factor kappa B } \\ \text { OGL } & \text { Outer granular layer } \\ \text { PC } & \text { Purkinje cells } \\ \text { TLR } & \text { Toll-like receptor } \\ \text { TNF- } \alpha & \text { Tumor necrosis factor-alpha } \\ \text { WM } & \text { White matter }\end{array}$

\section{Introduction}

Chorioamnionitis is an important problem in obstetrics today, affecting $20 \%$ of all term pregnancies and up to $60 \%$ of the preterm deliveries [1]. Chorioamnionitis is associated with premature rupture of membranes and premature labor as well as delivery [2-4]. It is an important risk factor for an adverse outcome, such as permanent brain injury and neurological handicaps. Recent clinical data underlines that chorioamnionitis is mainly related to cerebral white matter (WM) damage, including disseminated and focal necrosis and cystic lesions, clinically often presenting as cerebral palsy [5-9].

The mechanisms by which intrauterine inflammation might cause fetal brain injury are not yet fully understood. In human neonates, high concentrations of cytokines in the cord blood and the amniotic fluid, such as tumor necrosis factor-alpha (TNF- $\alpha$ ), interleukin (IL)6 , and IL $1 \beta$, increased the risk for periventricular leukomalacia [10]. Higher levels of pro-inflammatory cytokines were also expressed in the damaged areas of the brain $[11,12]$. Animal studies also provide evidence that the antenatal administration of endotoxins like lipopolysaccharide (LPS) causes a higher level of systemic cytokine expression leading to cerebral apoptotic cell death and gliosis in different animal species [13-19]. Therefore, it is thought that pro-inflammatory cytokines induce a multi-organ fetal inflammatory response syndrome leading to reactive astrogliosis and the loss of mainly immature oligodendrocytes [20, 21].

Despite the growing evidence linking intrauterine inflammation with an adverse neurological outcome, the exact consequences on the central nervous system remain unclear. Especially, cerebellar injury is often overlooked. Research evaluating the role of the cerebellum, especially its non-motor function, is still at a very early stage, but there is increasing evidence that the cerebellum is also involved in cognitive and affective disorders [22-27]. It seems likely that a disturbed development of the cerebellum during pregnancy and neonatal period may play a role in long-lasting motor, cognitive, and other behavioral changes [28]. The cerebellar cortex forms an important structure in the coordinative role of the cerebellum. Granule cells form a filter between mossy fiber inputs and the Purkinje cells, causing a strict selection of information [29]. An increase of granule cells may also influence the functionality of the cerebellar cortex. Any change in this structure may have implications for its function and could lead to motor, behavioral, or cognitive abnormalities.

It is important to know that almost half of the preterm infants with cerebral palsy show abnormalities in the cerebellum $[30,31]$. The cerebellum is particularly vulnerable during late gestation, since this is the period of active proliferation and migration of cerebellar granule cells, mainly in the outer granular layer [28, 32]. Later, granule cells migrate radially inward along the Bergmann glia from the outer granular layer, which will gradually disappear after birth, to the inner granular layer, which lies deep to the Purkinje cell layer $[33,34]$. There, they have to make initial contacts critical to establish the cerebellar circuitry [28]. It is becoming increasingly clear that injury and impaired development of the cerebellum may be associated with chorioamnionitis especially in ex-preterm infants $[22,25$, 35, 36]. Harmful events like chorioamnionitis during this period might interfere with the normal development of cerebellar granule cells. Other cerebellar cell populations, such as Purkinje cells, may be influenced by an altered granule cell development [37]. The fact that these mechanisms are that poorly understood underlines the importance of further research using this clinically relevant animal model to better understand pathological pathways in fetal cerebellar inflammation. In this present study, we wanted to prove the hypothesis that chorioamnionitis causes changes in the granule cell number and/or Purkinje cell number, associated with astrocytic changes, in the near-term fetal cerebellum.

In this present study, we used an intra-amniotic injection of LPS in an ovine model for chorioamnionitis. LPS is a component of a Gram-negative bacterial cell wall, which is responsible for most inflammatory responses in common bacterial infections. This model was chosen for several reasons. First, the injection of LPS, especially if administered intravenously, is often associated with circulatory changes in the fetus, causing a secondary hypoxia-ischemia which might contribute to brain damage [38, 39]. However, it is shown that intra-amniotic LPS can cause brain damage in the absence of a superimposed hypoxic-ischemic effect [19, 40, 41]. Second, fetal systemic inflammation has already previously been characterized and well described in this model. An intra-amniotic LPS injection caused an increase in interferon (IFN) $\gamma$, IL-6, and IL-8 in the cord plasma as well as an increase in TNF- $\alpha$ in the spleen [42]. 
Third, sheep have a long gestation, with several developmental anatomical and functional aspects of the fetal brain comparable to the humans. In this study, LPS was injected at 110 days of ovine gestation which is more or less similar to 28 weeks of gestation in the human fetus.

The purpose of this study was to determine if chorioamnionitis, induced by an intra-amniotic LPS injection, caused changes in cerebellar volumes and the number of neurons. To achieve this, $10 \mathrm{mg}$ of LPS was injected intraamniotically at 110 days of gestation (term $\approx 147$ days). At 140 days, cerebellar volume and the number of granule cells and Purkinje cells were assessed using design-based stereology. Astrogliosis was determined using a semiquantitative image analysis method.

\section{Materials and Methods}

\section{Animals}

All experimental procedures were approved by the Animal Ethics Board of the University of Maastricht according to Dutch governmental regulations. Timemated pregnant Texel ewes with singleton pregnancies were randomly assigned to the different groups. LPS was administered through ultrasound-guided injections as described previously [43]. Each ewe received a single dose of $10 \mathrm{mg}$ LPS (Escherichia coli 055:B5; SigmaAldrich, St. Louis, MO, USA) at gestational day (GD) 110 $(n=7)$. A dose of $10 \mathrm{mg}$ was chosen, since it has been demonstrated before to yield a robust and reproducible inflammation of the membranes [40, 42]. Before administration, the endotoxin was solubilized in $2 \mathrm{ml}$ saline and filtered through a $0.45-\mu \mathrm{m}$ filter. Control animals were treated identically $(n=7)$, but were injected with a single dose of saline into the amniotic fluid. Preterm lambs were delivered at GD 140 (term is $\approx$ GD147) by Cesarean section, and euthanized by decapitation. To prove the presence of a histological chorioamnionitis, the influx of inflammatory cells into the membranes was assessed. The numbers of inflammatory cells were ranked from few inflammatory cells $($ score $=1)$, moderate cell infiltration $($ score $=2)$, to extensive influx of cells $($ score $=3)$. The results of this validation are given in Fig. 1.

\section{Tissue Processing}

After opening the skull, brains were removed rapidly and halved in the mediosaggital line. The left cerebellum was immersion-fixed in $4 \%$ formalin for 3 months, cryoprotected $(10 \%, 20 \%$, and finally $30 \%$ sucrose in $0.1 \mathrm{M}$ Tris$\mathrm{HCl}$ buffer $24 \mathrm{~h}$ per solution at $4^{\circ} \mathrm{C}$ ), embedded in Tissuetek $^{\circledR}$ (Sakura Finetek), quickly frozen, and stored at $-80^{\circ} \mathrm{C}$

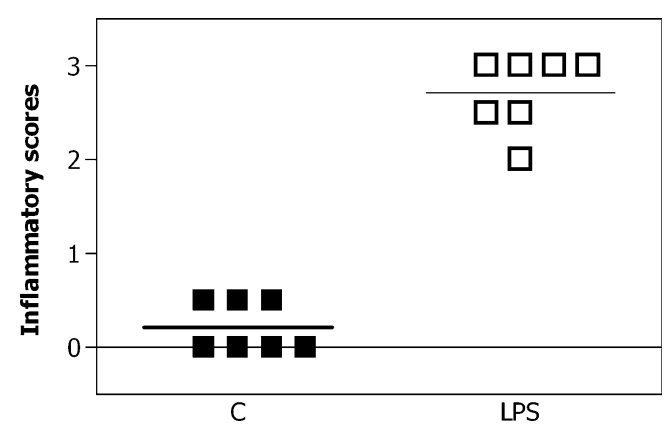

Fig. 1 Inflammatory score of the fetal membranes. Membranes were scored for the influx of inflammatory cells. The numbers of inflammatory cells were ranked from few inflammatory cells (score $=1)$, moderate cell infiltration (score $=2$ ), to extensive influx of cells (score=3). An intraamniotic injection of $10 \mathrm{mg}$ of LPS significantly increased the inflammation scores compared to control animals $(C)$

until further processing. Complete series of $50-\mu \mathrm{m}$-thick coronal sections were cut on a cryostat (Leica CM 3050; Leica, Nussloch, Germany). These sections were used for immunohistochemistry (glial fibrillary acidic protein (GFAP)).

The right cerebellum was frozen on a metal block in melting liquid nitrogen and stored at $-80^{\circ} \mathrm{C}$ until further processing. The cerebellum was entirely cut into complete series of $100-\mu \mathrm{m}$-thick coronal sections on a cryostat (Leica CM 3050; Leica, Nussloch, Germany). These series of sections were then divided into sub-series of every second section, yielding two series of 11 to 14 sections containing the cerebellum per animal. These sections were used for stereological analyses (Hoechst and Nissl staining).

\section{Immunohistochemistry}

Another series of every 12 th section of the left cerebellum was collected for immunohistochemical detection of GFAP. Briefly, GFAP labeling was conducted by incubating the sections $24 \mathrm{~h}$ with primary antibody (rabbit anti-GFAP; 1:800; DAKO, Glostrup, Denmark) at room temperature after rinsing with $0.05 \mathrm{M}$ Tris-buffered saline (TBS) and $0.01 \mathrm{M}$ Tris-buffered saline with $0.2 \%$ Triton X-100 (TBS$\mathrm{T})$ and blocking endogenous peroxidise activity with $0.3 \%$ $\mathrm{H}_{2} \mathrm{O}_{2}$. Following incubation and rinsing with $0.05 \mathrm{M}$ TBS and TBS-T, the sections were incubated in biotinylated secondary IgG antibodies (biotinylated donkey anti-rabbit IgG, 1:200; Jackson, West Grove, PA, USA) for $2 \mathrm{~h}$ at room temperature (RT), followed by $\mathrm{ABC}$ kit $(2 \mathrm{~h}$ at $\mathrm{RT}$; Vectastain, Burlingame, CA, USA). The sections were then simultaneously incubated with 3,3'-diaminobenzidine (Sigma, UIthoorn, The Netherlands) containing $30 \% \mathrm{H}_{2} \mathrm{O}_{2}$ in Tris$\mathrm{HCl}$ for $7 \mathrm{~min}$ at RT. Sections were rinsed with TBS. After dehydration, the sections were coverslipped using DePeX (Serva, Heidelberg, Germany). 


\section{Stereological Analysis}

One series of every 12th section of the right cerebellum was collected, mounted on glass slides (Superfrost Plus, Menzel, Braunschweig, Germany), dried, defatted with Triton X-100 (0.025\%; 20 min; Merck), and stained with cresyl violet $(0.01 \%, 5 \mathrm{~min})$. Slides were mounted and coverslipped using DePex (Serva, Heidelberg, Germany). These sections were used for volume measurements of the whole cerebellum and its layers, and for the assessment of the total number of granule cells in the inner granular cell layer (IGL). See Fig. 2a, b for examples of Nissl-stained sections.

Another series of every 12th section of the right cerebellum was collected, mounted on glass slides (Superfrost Plus, Menzel, Braunschweig, Germany), dried, and 15 min post-fixed using Somogyi fixation (0.2 M phosphate buffer, $20 \%$ paraformaldehyde, picric acid, and $25 \%$ glutaraldehyde ( $\mathrm{pH} 7.4)$ ). After rinsing, sections were stained 30 min with Hoechst (1:500, Sigma Chemical Co., St. Louis, MO, USA) and mounted with $80 \%$ glycerol in TBS. These sections were used for investigation of the total number of Purkinje cells (PCs). See Fig. $1 \mathrm{~b}$ for an example of a Purkinje cell and see Fig. 2c, d for an example of the Hoechst staining.

All stereologic analyses were performed with a computerized stereology workstation, consisting of a modified light microscope (Olympus BX50 with PlanApo objective $1.25 \times$ [numerical aperture (N.A.) $=0.04$ ] and UPlanApo objective $20 \times$ [oil; N.A. $=0.8$ ]; Olympus, Tokyo, Japan), motorized specimen stage for automatic sampling (Ludl Electronics; Hawthorne, NY, USA), CCD color video camera (HV-C20AMP; Hitachi, Tokyo, Japan), and stereology software (StereoInvestigator; MBF Bioscience, Williston, VT, USA). Using Nisslstained sections of the right cerebellum, delineations for volume measurements of different regions within the cerebellum, i.e., the inner and outer granular cell layer (IGL and OGL respectively), molecular layer (ML), and WM were analyzed using the Cavalieri's principle [44, $45]$ and point counting $[45,46]$ using a $1.25 \times$ objective. The delineation is shown in Fig. 1a. The total number of granule cells in the IGL (using Nissl-stained sections) and PCs (using sections stained with Hoechst) were estimated
Fig. 2 Delineation method. a An example of the delineation of the different layers of the cerebellum in a Hoechst-stained section. b An example of a Purkinje cell in a Hoechststained section (the asterisk corresponds to the nucleus)

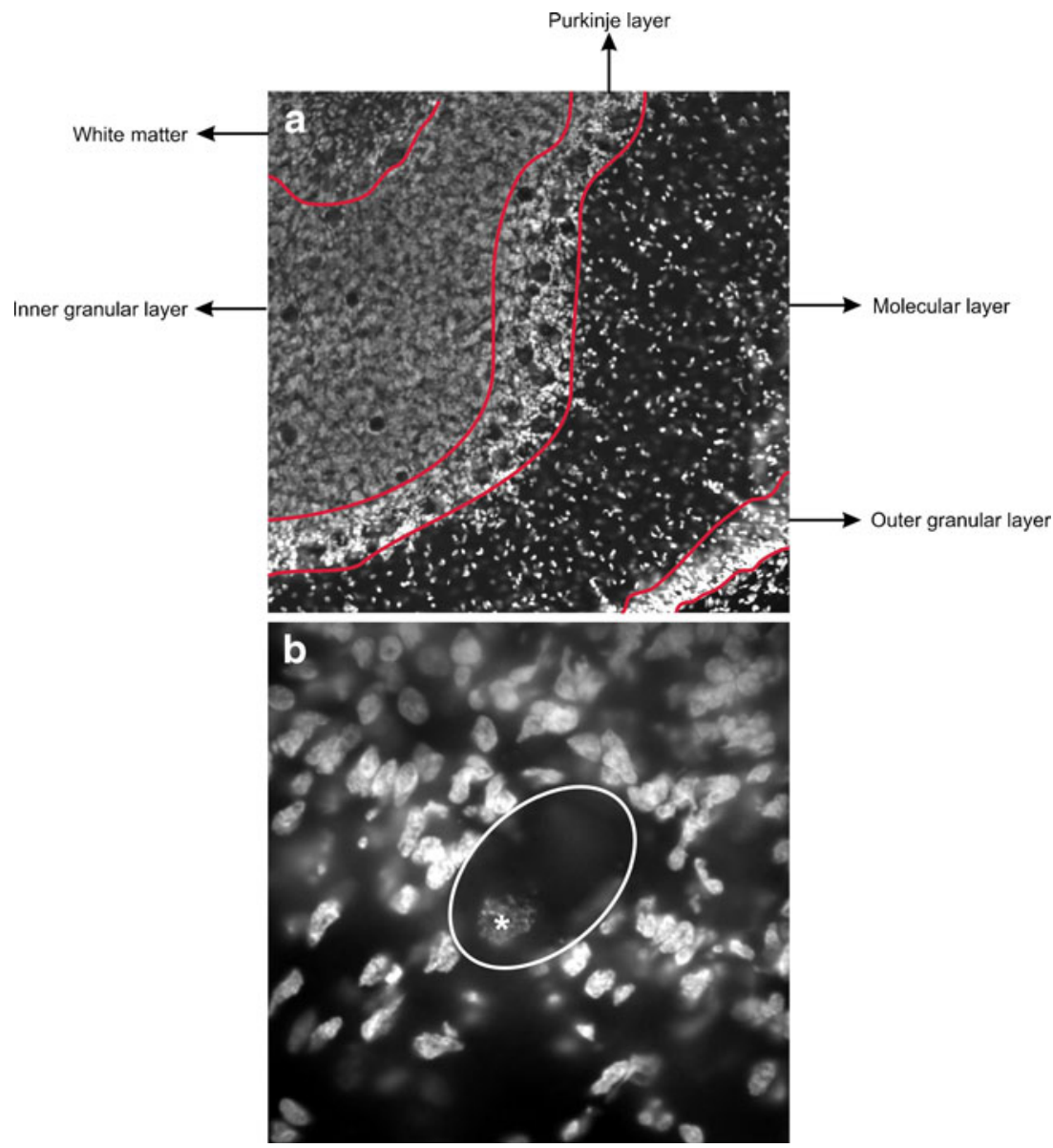


with the Optical Fractionator [45, 47]. All neurons whose nucleus top came into focus within unbiased virtual counting spaces distributed in a systematic random fashion throughout the delineated regions were counted $[45,46]$. Then, the total number of neurons was calculated from the numbers of counted neurons and the corresponding sampling probability. All details of the stereological analysis are summarized in Table 1.

Glial Fibrillary Acidic Protein Image Analysis

GFAP immunohistochemistry in the IGL, the ML, and the WM was measured by a semi-quantitative method. Three photographs were taken from each stained section within the different layers with the Olympus AX70 microscope connected to a digital camera (F-view, Olympus, Tokyo, Japan). To correct for a potential variability due to different lighting conditions, all images were collected under identical conditions. Photographs were analyzed using corresponding average gray values (ranging from 0 (black) to 255 (white)) and the percent area positive for GFAP staining, obtained with the NIH ImageJ software (http://rsb.info.nih.gov/ij/). Using a trial and error method, a threshold value was established and kept for all measurements. Blood vessels, tissue out of focus, or artifacts were excluded.

\section{Photography}

Photomicrographs as shown in Figs. 2, 3 and 4 were produced by digital photography using a MBF Bioscience Stereo Investigator Confocal Spinning Disk system (MBF Bioscience; Williston, VT), consisting of a modified Olympus BX51 fluorescence microscope (Olympus, Tokyo, Japan) with UPlanSApo objectives $(4 \times($ N.A. $=0.16), 10 \times$
$($ N.A. $=0.40), 40 \times($ N.A. $=0.90)$, and $60 \times($ N.A $=1.35)$; Olympus), customized spinning disk unit (Olympus), computer-controlled excitation and emission filter wheels (Olympus), three-axis high-accuracy computer-controlled stepping motor specimen stage $(4 \times 4$ Grid Encoded Stage; Ludl Electronic Products, Hawthorne, NY), linear $z$-axis position encoder (Ludl), ultra-high sensitivity monochrome electron multiplier CCD camera $(1,000 \times 1,000$ pixels, C9100-02; Hamamatsu Photonics, Hamamatsu City, Japan), and controlling software (MBF Bioscience).

Figures $2 \mathrm{a}$ and $3 \mathrm{a}$ are image montages composed of an average of 130 images for each figure, captured at a magnification of $4 \times$ (N.A. $=0.16$; Olympus) with use of the Virtual Slice module in the StereoInvestigator software (MBF Bioscience).

The final figure was created using Corel Draw v.11 (Corel, Ottawa, Canada). Only minor adjustments of contrast and brightness were made, without altering the appearance of the original materials.

\section{Statistical Analysis}

Mean and standard error of the mean were calculated for all investigated parameters for both LPS-injected and control animals. For each parameter, normality was tested using a Kolmogorov-Smirnov test. All results were normally distributed. Comparisons between LPS-injected and control animals were performed using generalized linear model multivariate analysis (MANOVA), with diagnosis (saline versus LPS) as a fixed factor and the sex and animal weight (ewe and fetus) as covariates. Statistical significance was established at $p<0.05$. Calculations were performed using Statistical Package for the Social Sciences (SPSS; Version 15.0 for Windows; SPSS, Chicago, IL, USA) and GraphPad Prism (Version 4.0 for Windows, GraphPad software, San Diego, CA, USA).

Table 1 Details of the stereologic analysis procedures

\begin{tabular}{|c|c|c|c|c|c|c|c|c|c|}
\hline & \multirow[b]{2}{*}{ Obj. 1} & \multirow[b]{2}{*}{ sla $x$, sla- $y[\mu \mathrm{m}]$} & \multicolumn{5}{|l|}{$\sum P$} & & \\
\hline & & & OGL & ML & IGL & WM & Total & & \\
\hline \multirow[t]{2}{*}{ Volumes } & $1.25 \times$ & 500 & 9.681 & 13.839 & 25.152 & 9.100 & 57.772 & & \\
\hline & Obj. 2 & $\sin -x, \sin -y[\mu \mathrm{m}]$ & $a\left[\mu \mathrm{m}^{2}\right]$ & $h[\mu \mathrm{m}]$ & $d[\mu \mathrm{m}]$ & $\sum \mathrm{OD}$ & $\sum N$ & $t[\mu \mathrm{m}]$ & $\mathrm{CE}_{\text {pred. } .}[n$ \\
\hline GCs & $20 \times$ & 1,700 & 10 & 10 & 4 & 224 & 699 & 8.8 & 0.038 \\
\hline $\mathrm{PCs}$ & $20 \times$ & 500 & 60 & 60 & 4 & 394 & 466 & 12.9 & 0.046 \\
\hline
\end{tabular}

$O G L$ outer granular cell layer, $M L$ molecular layer, $I G L$ inner granular cell layer, $W M$ white matter, Obj. 1 objective used for delineating the regions of interest and point counting, sla- $x$ and sla-y, distance between the points used for volume estimates in mutually orthogonal directions $\mathrm{x}$ and y, $\sum P$ average number of points counted, GCs granule cells, $P C s$ Purkinje cells, $O b j .2$ objective used for counting neurons, $\operatorname{sln}-x$ and $\operatorname{sln}-y$ distance between the unbiased virtual counting spaces used for counting neurons in mutually orthogonal directions $\mathrm{x}$ and $\mathrm{y} ; a$ and $h$ base and height of the unbiased virtual counting spaces, $d$ depth within the section at which the unbiased virtual counting spaces were placed, $\sum O D$ average number of unbiased virtual counting spaces used, $\sum N$ average number of neurons counted, $t$ measured actual average section thickness of the sections after histological processing, $C E_{\text {pred. }}[n]$ average predicted coefficient of error of the estimated total neuron numbers using the prediction method described by [44] 

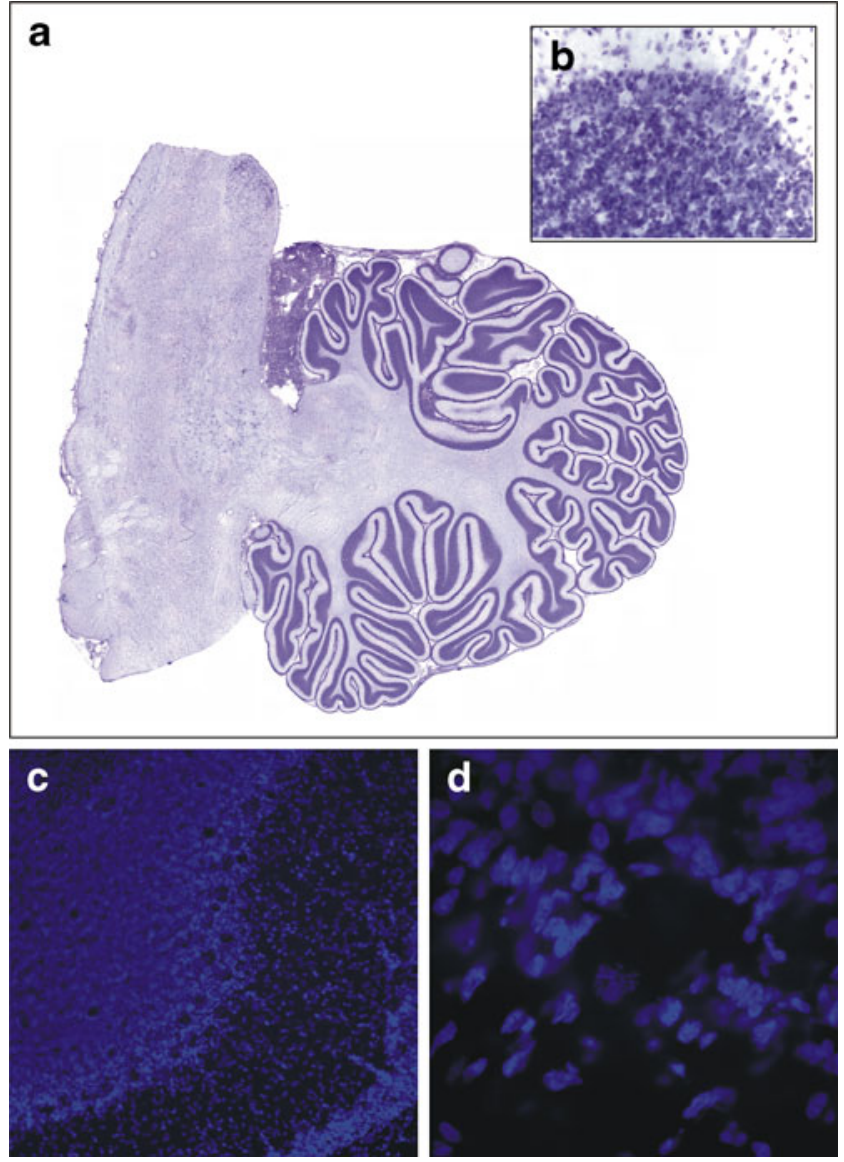

Fig. 3 Photomicrographs of Nissl- and Hoechst-stained sections. a An example of a virtual slice of a Nissl-stained section of the cerebellum. b A $40 \times$ magnification example of a Nissl-stained section used to count granular cells. c-d An example of a Hoechst-stained section at a low $(10 \times$; c) magnification showing the different cerebellar layers and high $(60 \times$; d $)$ magnification used to count Purkinje cells

\section{Results}

Inflammation Score of the Membranes

Inflammatory scores of the fetal membranes are given in Fig. 1. The scores from LPS animals ranged from 2 to 3, while the scores from control animals ranged between 0 and 0.5 . Therefore, LPS animals scored significantly higher that control animals.

\section{Volume Measurements}

The total cerebellum including the outer granular layer (OGL), the inner granular layer (IGL), the molecular layer (ML), and the WM of the LPS-exposed and control animals were identified on all analyzed sections (Fig. 2). Figure 5 depicts the mean volumes of the total cerebellum (Fig. 5a) as well as the OGL (Fig. 5b), the IGL (Fig. 5c), the ML
(Fig. 5d), and the WM (Fig. 5e). No significant differences were found between the LPS-exposed and control animals for any of the areas.

Total Number of Granule and Purkinje Cells

Figure 6 shows the mean number and density of granule cells (GCs; Fig. 6a, b) and Purkinje cells (PC; Fig. 6c). The LPS-exposed animals showed a significantly increased mean total number of GCs in the IGL $\left(+20.4 \% ; F_{1}=11.3\right.$, $p=0.015$ ), while there was no significant difference in the mean total PC number between the two groups. In addition, no significant difference was found between the two groups regarding the mean density of the GCs and the ratio between GCs and PCs (Fig. 6d). Sex did not have any significant influence on the variables investigated (data not shown).

\section{GFAP Immunoreactivity}

Astrocytes showed a strong GFAP immunoreactivity in both cell bodies as well as the processes in both groups in brains from LPS-injected animals as well as controls. This effect was found in all layers of the cerebellum, i.e. OGL, ML, IGL, and WM (Fig. 4). Figure 7 shows the results of GFAP immunoreactivity analysis. LPS-exposed animals were found to have a significantly lower gray value (0 (black) and 255 (white)), meaning a darker staining, than control animals $(p=0.0268$; Fig. $7 \mathrm{a})$ in the inner granular layer. Furthermore, LPS-exposed animals had a higher surface area (percent area) of GFAP-positive astrocytes ( $p=0.0436$; Fig. $7 d)$ in that layer.

\section{Discussion}

This study is the first detailed investigation of the effects of chorioamnionitis on the total number of neurons in the fetal ovine cerebellum using design-based stereology. Chorioamnionitis, induced by an intra-amniotic LPS injection at 110 days of gestation, resulted in several morphological alterations in the term cerebellum. Chorioamnionitis caused a massive increase $(+20.4 \%)$ in the number of cerebellar granule cells in the inner granular layer, while no changes were found in the number of Purkinje cells or the estimated volumes of the different cerebellar layers. In addition, the GFAP immunoreactivity - in terms of gray value and percent area of positive staining-was increased specifically in the inner granular layer.

Experimental data on the pathological effects of fetal inflammation or infection on the developing cerebellum are extremely scarce and limited to the use of either uteroplacental or fetal LPS administration in sheep [43, 
Fig. 4 Photomicrographs GFAP. a An example of a virtual slice of GFAP-stained section of the cerebellum. b An example of a $10 \times$ magnification photograph of the GFAP staining showing the different layers of the cerebellum. c-e High magnification photographs $(40 \times)$ of the molecular layer with the radial glial fibers (Bergmann glia) (c), the granular layer (d), and the white matter (e)
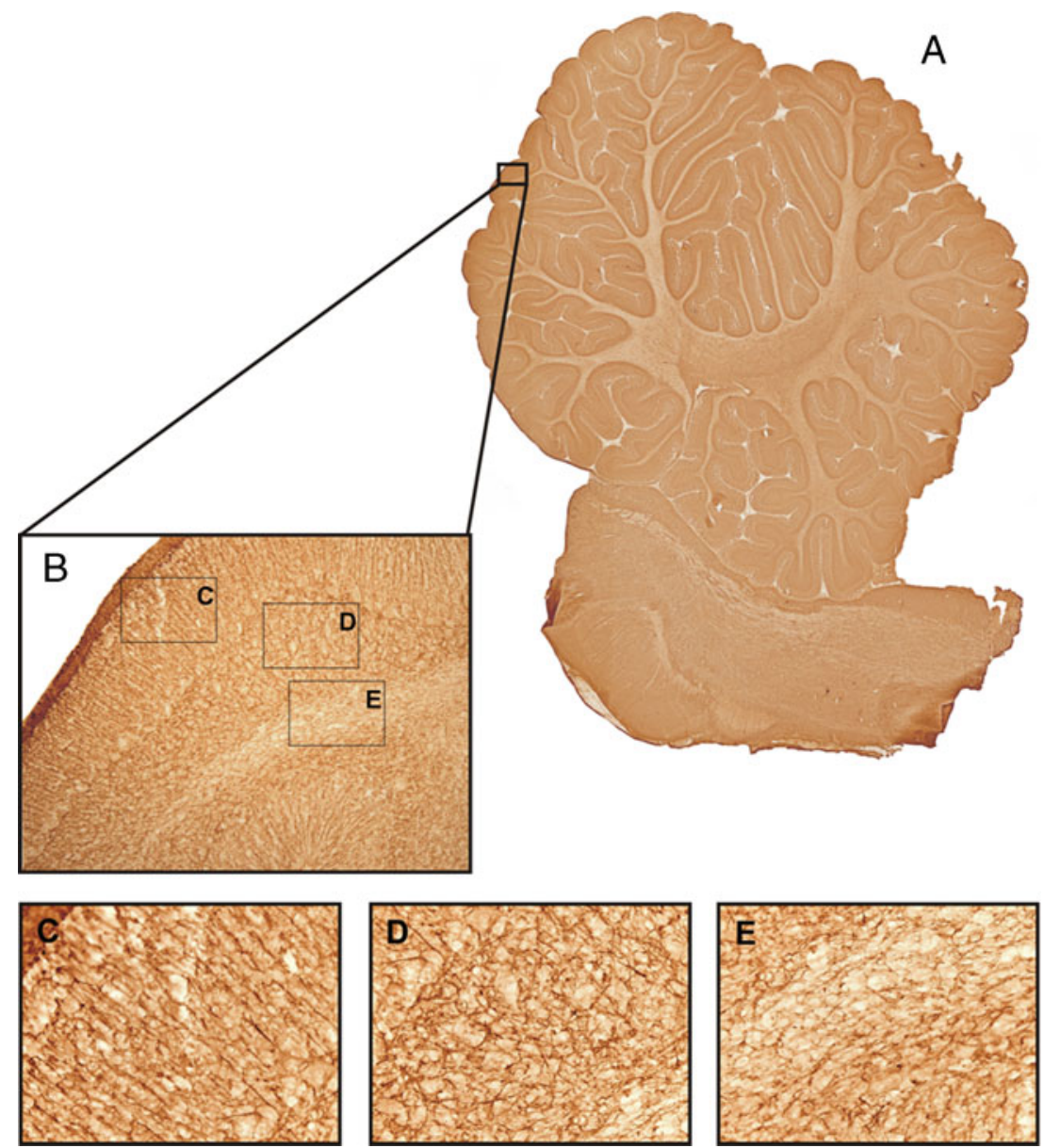

44]. An injection of LPS in the uterine artery during late gestation resulted in lipid peroxidation in all cerebellar layers as well as a compromised cerebellar blood-brain barrier [48]. These fetuses showed a dose-dependent increase in the number of GFAP-positive astrocytes in the cerebellar WM and the granular layer together with higher numbers of caspase 3-positive cells in the WM and molecular layer [48]. In contrast, an intravenous injection of LPS at 93-96 days of gestation only caused confined WM injury in the absence of obvious gray matter damage [49]. Cerebellar WM injury was demonstrated by the loss of oligodendrocytes, activated microglia, and an increased number of apoptotic cells [49]. However, surprisingly, Duncan and colleagues could not find clear cerebellar WM injury in the same model [50]. The discrepancies between the injury patterns found in our study and in the studies described above might be explained by differences in the experimental setup. Different timing of the insult with respect to brain maturity or variations in the route and the dose of LPS administration might explain the contradicting findings. Maybe, different regions within the central nervous system might be vulnerable during different periods of development.
As many studies clearly demonstrated that fetal inflammation, in particular pro-inflammatory cytokines, induced neuronal cell loss, we expected chorioamnionitis to trigger cell death leading to the loss of cerebellar neurons [43, 48, 49, 51]. However, we observed an increase in the number of granule cells in the IGL of the cerebellum. More cerebellar granule cells were also found by Schmitz et al. following a different type of insult, i.e., prenatal low-dose $\mathrm{X}$-radiation [52]. They ascribed the increase to the developmental stage of the brain. Moreover, a similar result was previously found in the hippocampus. Golan et al. reported an increase in hippocampal pyramidal and granular cells in mice offspring after maternal inflammation [53]. It is however important to keep in mind that the reported increase might be region-specific and restricted solely to the hippocampus. They interpreted this increase in hippocampal cells as part of a "regeneration program" to repair the injured tissue regulated by BDNF. Furthermore, the inconsistency of our study with the current literature might be explained by the different experimental time lines. Most studies investigated the acute effects of inflammation shortly after the administration of the toxic agent [43, 48, 49, 51]. However, in our study, the analyses were done 
Fig. 5 Cerebellar and layerspecific volume measurements The volume of the entire cerebellum (a), outer granular cell layer (b), inner granular cell layer (c), molecular layer (d), and white matter (b) of control (closed bars) and LPS-exposed animals (open bars). No significant difference was found between the LPS-exposed and the control animals for any of the areas. Abbreviations: $O G L$ outer granular layer; $I G L$ inner granular layer; $M L$ molecular layer, $W M$ white matter
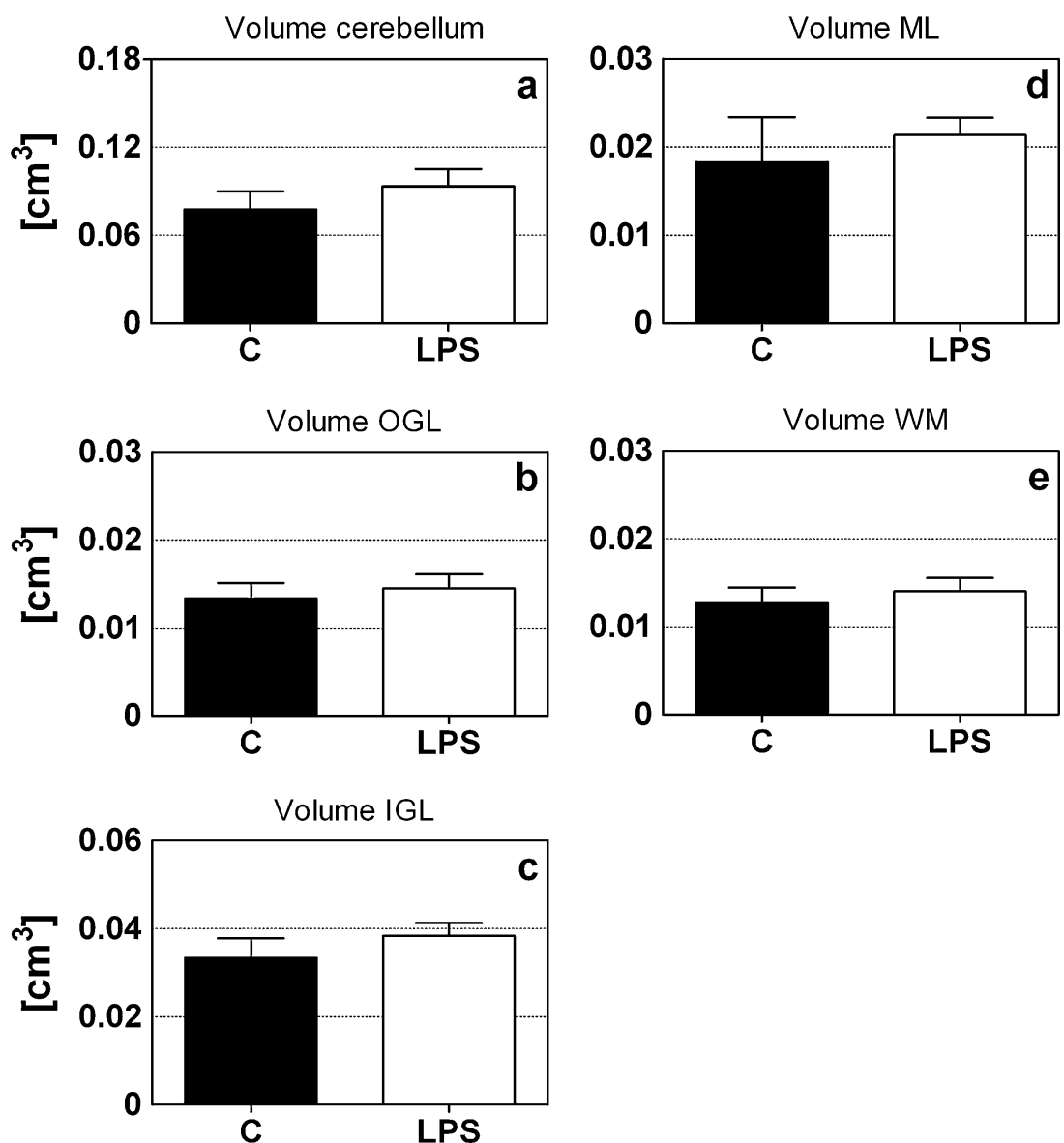

30 days after the LPS injection creating a time frame for the execution of possible recovery processes. Therefore, these rather unexpected findings might reflect the activation of a regenerative process or the disturbance of proper develop- ment. The increase in cerebellar granule cells might be caused by enhanced proliferation, enhanced cell survival, a reduced level of developmental apoptosis, or an accelerated migration of the granule cells from the outer to the inner
Fig. 6 The total number of granule and Purkinje cells. The mean total number (a) and density (b) of granule cells, the mean total number of Purkinje cells (c), and the ratio granule cells/Purkinje cells (d) of control (closed bars) and LPS-exposed animals (open bars). LPSinjected animals had significantly more granule cells than control animals. ${ }^{*} p<0.05$; MANOVA. $G C$ granule cells, $P C$ Purkinje cells
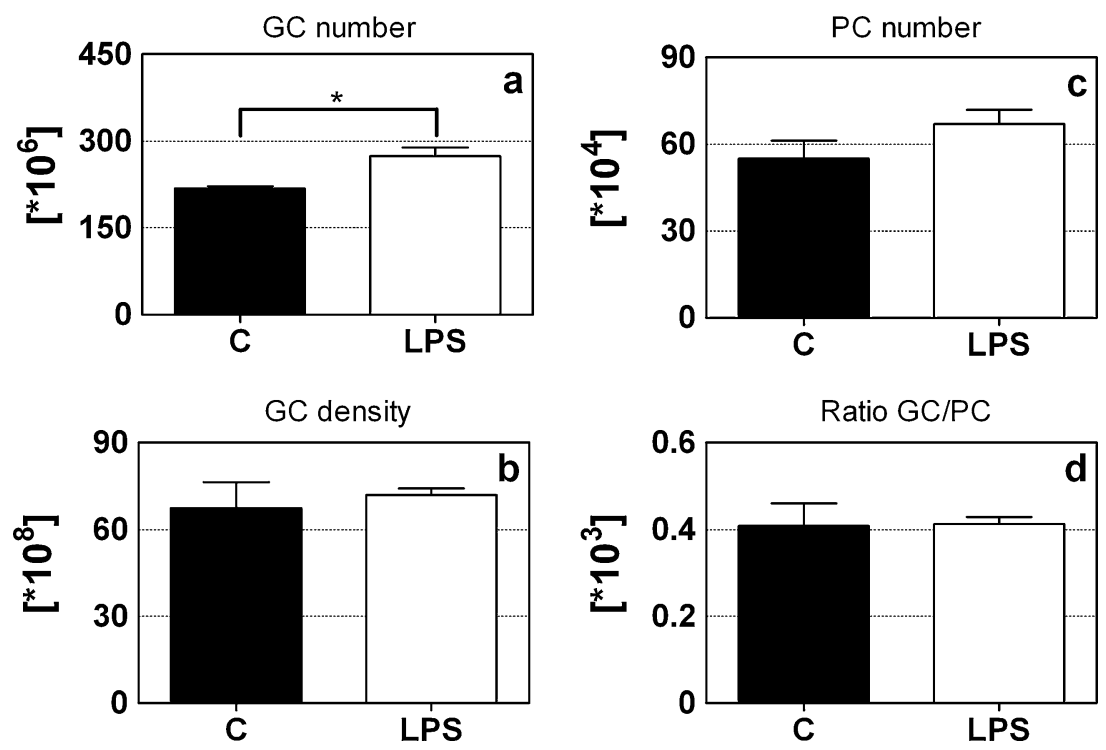
Fig. 7 GFAP immunoreactivity. GFAP immunoreactivity was measured by gray values $(0$ (black); 255 (white)) (a-c) and percent area of positive staining $(\mathbf{d}-\mathbf{f})$ in the inner granular layer, molecular layer, and white matter. LPS-exposed animals had a significantly lower gray value (i.e., darker staining) (a) and a significantly higher percent area (d) of GFAP-positive astrocytes in comparison with control animals. ${ }^{*} p<0.05$; MANOVA
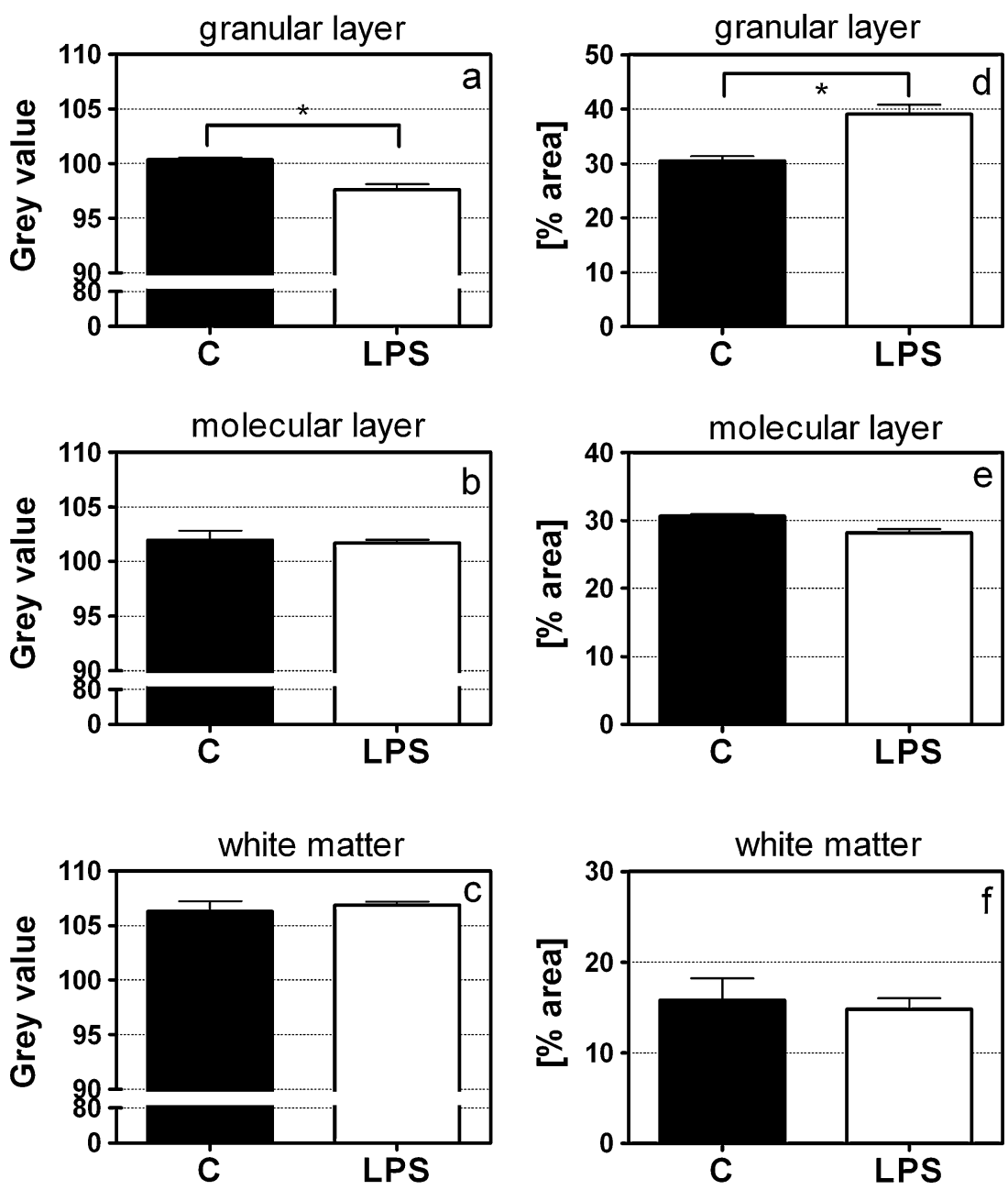

GL. However, which of these explanations might hold true awaits further research. The use of markers such as caspase 3 and Ki67, for apoptosis and proliferation, respectively, might be able to provide further evidence of whether this balance is altered. Hutton et al. already demonstrated an increased number of Ki67 proliferative cells in the sheep brain following an uteroplacental infection [54]. Particularly, during the third trimester, a period of rapid cerebellar growth takes place [35]. This phase of rapid growth might render the cerebellum particularly vulnerable. Late gestation is also characterized by a prominent proliferation and migration of cerebellar granule cells [55]. Considering this context, the conclusion that an infectious stimulus might significantly impair the development of certain brain cell populations by altering the proliferation-apoptosis balance or modulating the migration process does not appear farfetched.

No changes were found in the mean number of Purkinje cells, which is inconsistent with the current literature. It is now generally accepted that Purkinje cells are especially vulnerable in the developing brain. Purkinje cell damage and death have often been reported after asphyxia/hypoxia in experimental animal models and human post-mortem examinations, as well as after an infectious challenge [48, 56-59]. The absence of changes in the Purkinje cell layer in the present study might be explained by the fact that, in sheep, Purkinje cells are already present as a single layer by approximately 100 days of gestation and chorioamnionitis was only induced 10 days later (110GA) [32]. Formation of the inner granule layer, however, takes place exactly within this time frame with the layer being completed by day 120 of gestation [32].

Although in our model the mechanisms causing fetal cerebellar changes in the fetus remain unidentified, it is generally known that LPS, a pyrogenic component of Gram-negative bacteria, induces a downstream cascade of inflammatory responses via the toll-like receptor 4 (TLR4) and NF- $\mathrm{BB}$ activation stimulating macrophages to produce large amounts of cytokines [60-63]. Work by Kallapur and Kramer already demonstrated that an intra-amniotic LPS injection causes chorioamnionitis, which was quantified by an increased number of granulocytes in the amniotic fluid and the accumulation of inflammatory cells in the chorion/ 
amnion [42, 64]. These results were confirmed in the present study, where we showed an increased inflammatory score in the membranes. This histological chorioamnionitis is known to be associated with an enhanced cytokine expression in the chorion/amnion (i.e., TNF- $\alpha$, IL-1, IL-6, and IL-8) [64]. Kramer et al. also showed systemic inflammation by an increased level of IFN- $\gamma$, IL- 6 , and IL- 8 in the cord plasma as well as an increase of TNF- $\alpha$ in the spleen [42]. In the same model, we recently demonstrated that an intra-amniotic injection of $10 \mathrm{mg}$ LPS causes a significant increase in IL-1 $\beta$, IL-8, and TLR4 expression in the cerebellar cortex [unpublished data]. These data confirm an inflammatory response in the cerebellum.

In the brain, the transfer of maternal, placental, amniotic, and/or fetal cytokines might take place across an either intact or disrupted blood-brain barrier. Native cytokines might be produced by stimulated astrocytes and microglia [65-67]. It is commonly known that the main function of these pro-inflammatory cytokines is a contribution to the immune response. However, recently, it was demonstrated that cytokines may also play an important role in neuron development and function. TNF- $\alpha$ is involved in the regulation of the hippocampal development and neuron growth and survival, while IL-1 has shown to affect synaptic plasticity [68-72]. IL-6 has been shown to enhance survival of cultured neurons [73, 74]. Furthermore, pro-inflammatory cytokines, like IL-6, enhance the calcium response due to increased calcium release in the cell [75]. This may lead to increased proliferation of immature cerebellar granule cells as was shown in in vitro experiments [76, 77]. Furthermore, IL-6 shares a common intracellular subunit with neuronal growth factors, such as CNTF and LIF, suggesting that also IL-6 might affect neuronal development in the same way [78, 79].

Of note, it is often suggested that an intrauterine infection can affect the immature brain, not only by the production of pro-inflammatory cytokines but also by inducing cerebral hypoperfusion, leading to hypoxicischemic brain damage [38, 39, 80, 81]. However, previous studies already demonstrated that the intra-amniotic LPS application used in the present study can prevent the superimposed hypoxia-ischemia. Fetal arterial $\mathrm{pH}$, arterial carbon dioxide tension, fetal oxygen tension, and oxygen saturation were not altered [19, 40, 41]. For that reason, it seems unlikely that the cerebellar changes observed in this study could be partly attributed to the secondary cardiovascular effects of hypoxia.

Besides neuronal changes, this study also showed an increase in GFAP immunoreactivity in the inner granule cell layer. Such a response of astrocytes to harmful stimuli has been well established. Uteroplacental inflammation in sheep also resulted in an increase in the number of GFAP-positive cell bodies in the granule layer [48]. In different fetal animal models, enhanced cerebellar GFAP immunoreactivity was also reported as a reaction to hypoxia or chronic placental insufficiency [58, 82]. The precise role of astrogliosis still remains unclear. Recent evidence suggests that the process of astrogliosis has rather negative effects by interfering with the normal function of neuronal circuits and causing electrical instability [83]. Astrogliosis is also suggested to be beneficial because it might reestablish a protective barrier and support injured neurons by stabilizing the surrounding environment [83, 84]. Generally, neurons are highly dependent on functioning astrocytes for nutrition and maintenance of oxygen supply [85], which underlines the importance of an increase in reactive astrocytes during recovery.

Direct translation of these in vivo results into clinical practice is very complex. It is not clear yet if these cerebellar changes are associated with an adverse neurodevelopmental outcome. Although cerebellar injury has often been ignored, it is now becoming increasingly recognized that cerebellar pathology is linked to a wide range of deficits, such as motor, social, and cognitive disorders $[23,24,86,87]$. Therefore, one might speculate that the cerebellar changes seen in this study potentially account for some of the motor and/or non-motor deficits seen in neonates from pregnancies compromised by intrauterine infection and inflammation.

In summary, the current data clearly show that chorioamnionitis in the fetal sheep results in significant but paradoxical morphological cortical alterations in the inner granule layer of the cerebellum.

Conflict of interest notification With this statement, the authors certify that there is no conflict of interest (e.g., personal or financial) regarding the content discussed in this manuscript.

Open Access This article is distributed under the terms of the Creative Commons Attribution Noncommercial License which permits any noncommercial use, distribution, and reproduction in any medium, provided the original author(s) and source are credited.

\section{References}

1. Lahra MM, Jeffery HE. A fetal response to chorioamnionitis is associated with early survival after preterm birth. Am J Obstet Gynecol. 2004;190(1):147-51.

2. Greci LS, Gilson GJ, Nevils B, Izquierdo LA, Qualls CR, Curet LB. Is amniotic fluid analysis the key to preterm labor? A model using interleukin-6 for predicting rapid delivery. Am J Obstet Gynecol. 1998;179(1):172-8.

3. Yoon BH, Jun JK, Park KH, Syn HC, Gomez R, Romero R. Serum C-reactive protein, white blood cell count, and amniotic fluid white blood cell count in women with preterm premature rupture of membranes. Obstet Gynecol. 1996;88(6):1034-40. 
4. Yoon BH, Yang SH, Jun JK, Park KH, Kim CJ, Romero R. Maternal blood C-reactive protein, white blood cell count, and temperature in preterm labor: a comparison with amniotic fluid white blood cell count. Obstet Gynecol. 1996;87(2):231-7.

5. Yoon $\mathrm{BH}$, Park $\mathrm{CW}$, Chaiworapongsa $\mathrm{T}$. Intrauterine infection and the development of cerebral palsy. Bjog. 2003;110 Suppl 20:124-7.

6. Nelson KB, Willoughby RE. Infection, inflammation and the risk of cerebral palsy. Curr Opin Neurol. 2000;13(2):133-9.

7. De Vries LS, Van Haastert IL, Rademaker KJ, Koopman C, Groenendaal F. Ultrasound abnormalities preceding cerebral palsy in high-risk preterm infants. J Pediatr. 2004;144(6):815-20.

8. Inder TE, Anderson NJ, Spencer C, Wells S, Volpe JJ. White matter injury in the premature infant: a comparison between serial cranial sonographic and MR findings at term. AJNR Am J Neuroradiol. 2003;24(5):805-9.

9. Volpe JJ. Cerebral white matter injury of the premature infantmore common than you think. Pediatrics. 2003;112(1 Pt 1):17680.

10. Yoon BH, Jun JK, Romero R, Park KH, Gomez R, Choi JH, et al. Amniotic fluid inflammatory cytokines (interleukin-6, interleukin1beta, and tumor necrosis factor-alpha), neonatal brain white matter lesions, and cerebral palsy. Am J Obstet Gynecol. 1997;177 (1):19-26.

11. Kadhim H, Tabarki B, Verellen G, De Prez C, Rona AM, Sebire G. Inflammatory cytokines in the pathogenesis of periventricular leukomalacia. Neurology. 2001;56(10):1278-84.

12. Yoon BH, Romero R, Kim CJ, Koo JN, Choe G, Syn HC, et al. High expression of tumor necrosis factor-alpha and interleukin-6 in periventricular leukomalacia. Am J Obstet Gynecol. 1997;177 (2):406-11.

13. Gilles FH, Leviton A, Kerr CS. Endotoxin leucoencephalopathy in the telencephalon of the newborn kitten. J Neurol Sci. 1976;27 (2):183-91.

14. Rousset CI, Chalon S, Cantagrel S, Bodard S, Andres C, Gressens $\mathrm{P}$, et al. Maternal exposure to LPS induces hypomyelination in the internal capsule and programmed cell death in the deep gray matter in newborn rats. Pediatr Res. 2006;59(3):428-33.

15. Gilles FH, Averill Jr DR, Kerr CS. Neonatal endotoxin encephalopathy. Ann Neurol. 1977;2(1):49-56.

16. Yoon BH, Kim CJ, Romero R, Jun JK, Park KH, Choi ST, et al. Experimentally induced intrauterine infection causes fetal brain white matter lesions in rabbits. Am J Obstet Gynecol. 1997;177 (4):797-802.

17. Cai Z, Pan ZL, Pang Y, Evans OB, Rhodes PG. Cytokine induction in fetal rat brains and brain injury in neonatal rats after maternal lipopolysaccharide administration. Pediatr Res. 2000;47 (1):64-72

18. Duncan JR, Cock ML, Suzuki K, Scheerlinck JP, Harding R, Rees SM. Chronic endotoxin exposure causes brain injury in the ovine fetus in the absence of hypoxemia. J Soc Gynecol Investig. 2006;13(2):87-96.

19. Nitsos I, Rees SM, Duncan J, Kramer BW, Harding R, Newnham $\mathrm{JP}$, et al. Chronic exposure to intra-amniotic lipopolysaccharide affects the ovine fetal brain. J Soc Gynecol Investig. 2006;13 (4):239-47.

20. Bell MJ, Hallenbeck JM, Gallo V. Determining the fetal inflammatory response in an experimental model of intrauterine inflammation in rats. Pediatr Res. 2004;56(4):541-6.

21. Leviton A, Gilles F. Ventriculomegaly, delayed myelination, white matter hypoplasia, and "periventricular" leukomalacia: how are they related? Pediatr Neurol. 1996;15(2):127-36.

22. Limperopoulos C, Bassan H, Gauvreau K, Robertson Jr RL, Sullivan NR, Benson CB, et al. Does cerebellar injury in premature infants contribute to the high prevalence of long-term cognitive, learning, and behavioral disability in survivors? Pediatrics. 2007;120(3):584-93.
23. Limperopoulos C, Robertson RL, Sullivan NR, Bassan H, du Plessis AJ. Cerebellar injury in term infants: clinical characteristics, magnetic resonance imaging findings, and outcome. Pediatr Neurol. 2009;41(1):1-8.

24. Hoppenbrouwers SS, Schutter DJ, Fitzgerald PB, Chen R, Daskalakis ZJ. The role of the cerebellum in the pathophysiology and treatment of neuropsychiatric disorders: a review. Brain Res Rev. 2008;59(1):185-200.

25. Parker J, Mitchell A, Kalpakidou A, Walshe M, Jung HY, Nosarti C, et al. Cerebellar growth and behavioural \& neuropsychological outcome in preterm adolescents. Brain. 2008;131(Pt 5):1344-51.

26. Allin M, Matsumoto H, Santhouse AM, Nosarti C, AlAsady MH, Stewart AL, et al. Cognitive and motor function and the size of the cerebellum in adolescents born very pre-term. Brain. 2001;124 (Pt 1):60-6.

27. Schmahmann JD, Sherman JC. The cerebellar cognitive affective syndrome. Brain. 1998;121:561-79.

28. Paladini D, Volpe P. Posterior fossa and vermian morphometry in the characterization of fetal cerebellar abnormalities: a prospective three-dimentional ultrasound study. Ultrasound Obstet Gynecol. 2006;27:482-9.

29. Solinas S, Nieus T, D'Angelo E. A realistic large-scale model of the cerebellum granular layer predicts circuit spatio-temporal filtering properties. Front Cell Neurosci. 2010;4:12.

30. Bodensteiner JB, Johnsen SD. Cerebellar injury in the extremely premature infant: newly recognized but relatively common outcome. J Child Neurol. 2005;20(2):139-42.

31. Johnsen SD, Bodensteiner JB, Lotze TE. Frequency and nature of cerebellar injury in the extremely premature survivor with cerebral palsy. J Child Neurol. 2005;20(1):60-4.

32. Rees S, Harding R. The effects of intrauterine growth retardation on the development of the Purkinje cell dendritic tree in the cerebellar cortex of fetal sheep: a note on the ontogeny of the Purkinje cell. Int J Dev Neurosci. 1988;6(5):461-9.

33. Friede RL. Dating the development of human cerebellum. Acta Neuropathol. 1973;23(1):48-58.

34. Rakic P. Neuron-glia relationship during granule cell migration in developing cerebellar cortex. A golgi and electron microscopy study in Macacus rhesus. J Comp Neurol. 2004;141 (3):283-312.

35. Limperopoulos C, Soul JS, Gauvreau K, Huppi PS, Warfield SK, Bassan $\mathrm{H}$, et al. Late gestation cerebellar growth is rapid and impeded by premature birth. Pediatrics. 2005;115(3):688-95.

36. Nosarti C, Giouroukou E, Healy E, Rifkin L, Walshe M, Reichenberg A, et al. Grey and white matter distribution in very preterm adolescents mediates neurodevelopmental outcome. Brain. 2008;131(Pt 1):205-17.

37. Jacobson M. Histogenesis and morphogenesis of cortical cultures. In: Jacobson M, editor. Developmental neurobiology. New York: Plenum; 1991. p. 401-51.

38. Feng SY, Phillips DJ, Stockx EM, Yu VY, Walker AM. Endotoxin has acute and chronic effects on the cerebral circulation of fetal sheep. Am J Physiol Regul Integr Comp Physiol. 2009;296(3): R640-50.

39. Garnier Y, Coumans A, Berger R, Jensen A, Hasaart TH. Endotoxemia severely affects circulation during normoxia and asphyxia in immature fetal sheep. J Soc Gynecol Investig. 2001;8 (3): $134-42$

40. Jobe AH, Newnham JP, Willet KE, Moss TJ, Gore Ervin M, Padbury JF, et al. Endotoxin-induced lung maturation in preterm lambs is not mediated by cortisol. Am J Respir Crit Care Med. 2000;162(5):1656-61.

41. Nitsos I, Moss TJ, Cock ML, Harding R, Newnham JP. Fetal responses to intra-amniotic endotoxin in sheep. J Soc Gynecol Investig. 2002;9(2):80-5. 
42. Kramer BW, Moss TJ, Willet KE, Newnham JP, Sly PD, Kallapur $\mathrm{SG}$, et al. Dose and time response after intraamniotic endotoxin in preterm lambs. Am J Respir Crit Care Med. 2001;164(6):982-8.

43. Gavilanes AW, Strackx E, Kramer BW, Gantert M, Van den Hove $\mathrm{D}$, Steinbusch $\mathrm{H}$, et al. Chorioamnionitis induced by intraamniotic lipopolysaccharide resulted in an interval-dependent increase in central nervous system injury in the fetal sheep. Am J Obstet Gynecol. 2009;200(4):437 e1-8.

44. Cavalieri, B., Geometria indivisibilibus continuorum. Bonoiae: Typis Clementis Ferronij. 1635.

45. Schmitz C, Hof PR. Design-based stereology in neuroscience. Neuroscience. 2005;130(4):813-31.

46. Gundersen HJ, Jensen EB. The efficiency of systematic sampling in stereology and its prediction. J Microsc. 1987;147(Pt 3):229-63.

47. West MJ, Slomianka L, Gundersen HJ. Unbiased stereological estimation of the total number of neurons in thesubdivisions of the rat hippocampus using the optical fractionator. Anat Rec. 1991;231(4):482-97.

48. Hutton LC, Castillo-Melendez M, Walker DW. Uteroplacental inflammation results in blood brain barrier breakdown, increased activated caspase 3 and lipid peroxidation in the late gestation ovine fetal cerebellum. Dev Neurosci. 2007;29(45):341-54.

49. Dean JM, Farrag D, Zahkouk SA, El Zawahry EY, Hagberg H, Kjellmer I, et al. Cerebellar white matter injury following systemic endotoxemia in preterm fetal sheep. Neuroscience. 2009;160(3):606-15.

50. Duncan JR, Cock ML, Scheerlinck JP, Westcott KT, McLean C, Harding $\mathrm{R}$, et al. White matter injury after repeated endotoxin exposure in the preterm ovine fetus. Pediatr Res. 2002;52(6):9419.

51. Conroy SM, Nguyen V, Quina LA, Blakely-Gonzales P, Ur C, Netzeband JG, et al. Interleukin-6 produces neuronal loss in developing cerebellar granule neuron cultures. J Neuroimmunol. 2004;155(1-2):43-54.

52. Schmitz C, Otto U, Korr H. More cerebellar granule cells following prenatal low-dose X-irradiation. Brain Res. 2000;872 (1-2):250-3.

53. Golan HM, Lev V, Hallak M, Sorokin Y, Huleihel M. Specific neurodevelopmental damage in mice offspring following maternal inflammation during pregnancy. Neuropharmacology. 2005;48 (6):903-17.

54. Hutton LC, Yan E, Yawno T, Castillo-Melendez M, Hirst JJ, Walker DW. Injury of the developing cerebellum: a brief review of the effects of endotoxin and asphyxial challenges in the late gestation sheep fetus. Cerebellum. 2007;3:1-10.

55. Berry M, Bannister LH, Standring SM. Nervous system. In: Williams PL, editor. Gray's anatomy. Edinburgh: Churchill Livingstone; 1995. p. 901-1395.

56. Rees S, Stringer M, Just Y, Hooper SB, Harding R. The vulnerability of the fetal sheep brain to hypoxemia at midgestation. Brain Res Dev Brain Res. 1997;103(2):103-18.

57. Castillo-Melendez M, Chow JA, Walker DW. Lipid peroxidation, caspase-3 immunoreactivity, and pyknosis in late-gestation fetal sheep brain after umbilical cord occlusion. Pediatr Res. 2004;55 (5):864-71.

58. Lee C, Kim DW, Jeon GS, Roh EJ, Seo JH, Wang KC, et al. Cerebellar alterations induced by chronic hypoxia: an immunohistochemical study using a chick embryonic model. Brain Res. 2001;901(1-2):271-6.

59. Yan E, Castillo-Melendez M, Nicholls T, Hirst J, Walker D. Cerebrovascular responses in the fetal sheep brain to low-dose endotoxin. Pediatr Res. 2004;55(5):855-63.

60. Poltorak A, He X, Smirnova I, Liu MY, Van Huffel C, Du X, et al. Defective LPS signaling in $\mathrm{C} 3 \mathrm{H} / \mathrm{HeJ}$ and $\mathrm{C} 57 \mathrm{BL} / 10 \mathrm{ScCr}$ mice: mutations in Tlr4 gene. Science. 1998;282(5396):2085-8.
61. Wang X, Rousset CI, Hagberg H, Mallard C. Lipopolysaccharideinduced inflammation and perinatal brain injury. Semin Fetal Neonatal Med. 2006;11(5):343-53.

62. Akira S. TLR signaling. Curr Top Microbiol Immunol. 2006;311:1-16.

63. Briscoe T, Duncan J, Cock M, Choo J, Rice G, Harding R, et al. Activation of NF-kappaB transcription factor in the preterm ovine brain and placenta after acute LPS exposure. J Neurosci Res. 2006;83(4):567-74.

64. Kallapur SG, Willet KE, Jobe AH, Ikegami M, Bachurski CJ. Intra-amniotic endotoxin: chorioamnionitis precedes lung maturation in preterm lambs. Am J Physiol Lung Cell Mol Physiol. 2001;280(3):L527-36.

65. Yang GY, Gong C, Qin Z, Liu XH, Lorris Betz A. Tumor necrosis factor alpha expression produces increased blood-brain barrier permeability following temporary focal cerebral ischemia in mice. Brain Res Mol Brain Res. 1999;69(1):135-43.

66. Dammann O, Leviton A. Maternal intrauterine infection, cytokines, and brain damage in the preterm newborn. Pediatr Res. 1997;42(1):1-8.

67. Pang Y, Cai Z, Rhodes PG. Effects of lipopolysaccharide on oligodendrocyte progenitor cells are mediated by astrocytes and microglia. J Neurosci Res. 2000;62(4):510-20.

68. Yang L, Lindholm K, Konishi Y, Li R, Shen Y. Target depletion of distinct tumor necrosis factor receptor subtypes reveals hippocampal neuron death and survival through different signal transduction pathways. J Neurosci. 2002;22(8):3025-32.

69. Neumann H, Schweigreiter R, Yamashita T, Rosenkranz K, Wekerle H, Barde YA. Tumor necrosis factor inhibits neurite outgrowth and branching of hippocampal neurons by a rhodependent mechanism. J Neurosci. 2002;22(3):854-62.

70. Cunningham AJ, Murray CA, O'Neill LA, Lynch MA, O'Connor JJ. Interleukin-1 beta (IL-1 beta) and tumour necrosis factor (TNF) inhibit long-term potentiation in the rat dentate gyrus in vitro. Neurosci Lett. 1996;203(1):17-20.

71. Tancredi V, D'Arcangelo G, Grassi F, Tarroni P, Palmieri G, Santoni A, et al. Tumor necrosis factor alters synaptic transmission in rat hippocampal slices. Neurosci Lett. 1992;146(2):176-8.

72. Tancredi V, D'Antuono M, Cafe C, Giovedi S, Bue MC, D'Arcangelo G, et al. The inhibitory effects of interleukin- 6 on synaptic plasticity in the rat hippocampus are associated with an inhibition of mitogen-activated protein kinase ERK. J Neurochem. 2000;75(2):634-43.

73. Brenneman DE, Schultzberg M, Bartfai T, Gozes I. Cytokine regulation of neuronal survival. J Neurochem. 1992;58(2):45460.

74. Hama T, Miyamoto M, Tsukui $\mathrm{H}$, Nishio $\mathrm{C}$, Hatanaka $\mathrm{H}$. Interleukin- 6 as a neurotrophic factor for promoting the survival of cultured basal forebrain cholinergic neurons from postnatal rats. Neurosci Lett. 1989;104(3):340-4.

75. Holliday J, Parsons K, Curry J, Lee SY, Gruol DL. Cerebellar granule neurons develop elevated calcium responses when treated with interleukin-6 in culture. Brain Res. 1995;673(1):141-8.

76. Borodinsky LN, Fiszman ML. Extracellular potassium concentration regulates proliferation of immature cerebellar granule cells. Brain Res Dev Brain Res. 1998;107(1):43-8.

77. Mhyre TR, Maine DN, Holliday J. Calcium-induced calcium release from intracellular stores is developmentally regulated in primary cultures of cerebellar granule neurons. J Neurobiol. 2000;42(1):134-47.

78. Ip NY, Nye SH, Boulton TG, Davis S, Taga T, Li Y, et al. CNTF and LIF act on neuronal cells via shared signaling pathways that involve the IL-6 signal transducing receptor component gp130. Cell. 1992;69(7):1121-32.

79. Kishimoto T, Akira S, Taga T. Interleukin- 6 and its receptor: a paradigm for cytokines. Science. 1992;258(5082):593-7. 
80. Saito M, Matsuda T, Okuyama K, Kobayashi Y, Kitanishi R, Hanita $\mathrm{T}$, et al. Effect of intrauterine inflammation on fetal cerebral hemodynamics and white-matter injury in chronically instrumented fetal sheep. Am J Obstet Gynecol. 2009;200 (6):663 e1-663 e11.

81. Coumans AB, Garnier Y, Supcun S, Jensen A, Berger R, Hasaart $\mathrm{TH}$. The effects of low-dose endotoxin on the umbilicoplacental circulation in preterm sheep. J Soc Gynecol Investig. 2004;11 (5):289-93.

82. Mallard EC, Rees S, Stringer M, Cock ML, Harding R. Effects of chronic placental insufficiency on brain development in fetal sheep. Pediatr Res. 1998;43(2):262-70.

83. Reier P. Gliosis following CNS injury: the anatomy of astrocytic scars and their influences on axonal elongation. In: Vernadakis A,
Fedoroff S, editors. Astrocytes, cell biology and pathology of astrocytes. New York: Academic; 1986. p. 263-324.

84. Montgomery DL. Astrocytes: form, functions, and roles in disease. Vet Pathol. 1994;31(2):145-67.

85. Magistretti PJ, Pellerin L. Cellular bases of brain energy metabolism and their relevance to functional brain imaging: evidence for a prominent role of astrocytes. Cereb Cortex. 1996;6(1):50-61.

86. Allen G, Courchesne E. The cerebellum and non-motor function: clinical implications. Mol Psychiatry. 1998;3(3):207-10.

87. Allen G, Courchesne E. Differential effects of developmental cerebellar abnormality on cognitive and motor functions in the cerebellum: an fMRI study of autism. Am J Psychiatry. 2003;160 (2):262-73. 